\title{
Applying the Conceptual-Model of Progressive Development to the Contaminated Aquifer Underlying Israel's Coastal Plain
}

\author{
Yakov Livshitz ${ }^{1}$, Arie S. Issar ${ }^{2}$ \\ ${ }^{1}$ Hydrological Service of Israel, Jerusalem, Israel \\ ${ }^{2}$ Ben-Gurion University, Jerusalem, Israel \\ E-mail:yakovl20@water.gov.il,issar@bgu.ac.il \\ Received November 3, 2009; revised November 30, 2009; accepted January 20, 2010
}

\begin{abstract}
The last ten years of moderate to low precipitation rates in Israel may be a confirmation of the forecast, based on historical data, that recent, repeated droughts are a function of global warming. In this case the conventional policy of "Sustainable Development" is not sufficient to avert the impact of diminution of precipitation on Israel's water supply. Instead, a policy of "Progressive Development" is proposed, which aims to exploit, stage by stage, first the water resources most available and at lowest cost until they are exhausted. Once this stage is under execution, progressive steps are taken to develop more costly resources by advanced methods of exploitation. A case study of such a development plan is the controlled deterioration of the water quality of the coastal plain aquifer of Israel.
\end{abstract}

Keywords: Progressive Development, Global Warming, Water Resources, Water Quality, Coastal Aquifer

\section{Introduction}

Paleo-climate investigations indicate that warm climates during historical periods have caused droughts and famine in the Middle East [1]. Recent climatologic data reveal a decline of the average precipitation in this region, which is assumed to be a result of the current global warming process [2]. As population growth continues in this region the problem of adequate water supply for the population, domestic as well for other purposes, will become more and more strenuous. This problem, due to this chain of events of diminishing of precipitation and thus the diminishing of water resources while there is an ongoing increase of demand, raises the question whether the conventional policy of "Sustainable Development"1 can be followed. In other words the question is whether this ideal goal of sustaining of natural resources can be maintained when these resources disappear. In broader terms the question is whether the concern for the future generations does not risk the survival of the present generation. The first answer is that the survival of the pre-

\footnotetext{
${ }^{1}$ The Brundtland Report (1987) on Our Common Future defined sustainable development as development that meets the needs of the present without compromising the ability of future generations to meet their own needs.
}

sent generation is the basic condition for any future. The second part of this answer will be that in order to guarantee the survival of present and future generations courage is required to develop new resources even when this demands broad and deep changes in the natural environment. Such changes, among others, are the drying up of the summer flow of springs, by pumping and lowering the groundwater table, in order to prepare an empty volume of storage for recharge by winter rains, the use of reclaimed sewage for irrigation as well as recharge of reclaimed sewage to groundwater and thus reducing the quality of the water in the subsurface, introduction of desalinization projects, either of seawater, or brackish groundwater for all purposes, the mining of fossil water etc.

As all these steps and others in principal take the risk of comprising the quality and even the quantity of water for future generations, and thus do not follow the basic principle of "Sustainable Development" they have to follow a plan of trial, error, correction, renovation and vice versa. Such a plan, under the title of "Progressive Development" has been suggested by Issar $[3,4]$. This plan comprises a regional development plan, the first phases of which will involve the exploitation of the most available and low cost water resources. During the more 
advanced stages of the plan the development of the water resources will progress stage by stage to more costly resources and advanced methods of exploitation.

This plan of "Progressive Development" was first formulated to answer the general problem of famine and thirst caused by the drying up of water resources in the belt of semi-arid and arid regions bordering the global desert belts. Yet this plan is based on Israel's historic achievements in developing its water resources. This country, which is also situated in the same belt of aridity, may serve as a case study for "Progressive Development" of its water resources and has already reached a relatively highly advanced stage of development. Thus in the future, especially if the forecast of a dry period is confirmed, Israel's additional supply will depend mainly on the desalination of seawater and partial desalination of brackish water, reclaimed sewage and purification of contaminated groundwater.

The water supply of Israel is based on three main water resources: the Sea of Galilee ( $\sim 80$ million cubic meters per year $[\mathrm{MCM} / \mathrm{Y}])$, the Yarkon Taninim Mountain Aquifer $(\sim 360 \mathrm{MCM} / \mathrm{Y})$ and the Coastal Plain Aquifer $(\sim 420 \mathrm{MCM} / \mathrm{Y})$. Both red lines and green lines have been defined for these water resources where the red lines describe the minimal-allowed water level. Dropping below the red lines may cause damage to water quality (chemical or/and biological). The green lines are defined as the optimal operation levels. The total water storage between red and green lines for all three resources is estimated as $1440 \mathrm{MCM}[5,6]$.

According to the plans of the Israel Water Authority, by the year 2013 the quantity of desalinized seawater will reach about 550 million cubic meters $(\mathrm{MCM}) / \mathrm{Y}$, and by the year 2020 Israel will be desalinating about 750 $(\mathrm{MCM}) / \mathrm{Y}$. Taking into account that already in 2007 urban consumption reached about $760 \mathrm{MCM} / \mathrm{Y}$, further population growth, more years of drought and the occurence of extremely rainy years (like 1968/69 1991/02) storage of drinking water quality groundwater (even after being mixed with desalinized seawater) has to be prepared. Due to hydraulic properties (relatively high storativity- $15-35 \%$ and relatively low hydraulic conductivity-5-20 m/day) and geographic location (along the sea coast and close to main consumption area) the Coastal Plain Aquifer is the most suitable aquifer for storage (Figure 1).

\section{The Coastal Plain Aquifer (CPA), Present Situation}

The CPA is bordered on the west by the sea and on the east by the foothills region. On the north it is bordered by the Mount Carmel foothills and to the south by the Negev foothills region. During the Neogene, the Coastal Plain was covered by the sea in which were deposited shallow marine marls (Saqiye Group). During the Quaternary, transgressions and regressions re-occurred, most probably in connection with the glacial and inter-glacial phenomena. During the regressions marine sandstone were deposited, while during transgression the mainly clays and loams. Along the ancient shore-lines longitudinal sandstone ridges were formed [7].

The permeable sandstone and sands form the aquiferous part of the CPA which is divided into sub-aquifers by the semi-permeable loams and impermeable clays. Figure 2 shows how this division occurs only in the western part of the CPA to a distance of up to $7 \mathrm{~km}$ eastward from the sea. The upper most sequence forms a phreatic sub-aquifer, which is recharged directly from precipitation and leakage from irrigation. The leakages from the surface and phreatic zone cause pollution, which affects only this uppermost sub-aquifer. In some parts of the CPA, over-pumping and decline of the groundwater table has caused penetration of the sea water into the aquifer, which varies in the different parts of the CPA according to local geology and the position of the hydraulic head in each region and in each sub-aquifer. In the central and eastern part of the CPA, the extension of the inter-fingering impermeable layers disappears and the sub-aquifers merge together to form one phreatic system. In these areas, the Coastal Plain Aquifer is subdivided only by semi-permeable loams, which retard but do not prevent vertical flow (Figure 2).

The Coastal Plain aquifer is recharged by rain falling on its outcrops and by the return flow from irrigation, artificial recharge and brackish water inflow from the east. Water from floods coming from the mountains' streams also infiltrates alluvial fans and recharges the aquifer. In general, the ground water flow in the Coastal Plain aquifer is from east to west except in areas where excess pumping causes cones of depression along with lowering of the water table. In these areas the flow is directed towards the groundwater table depressions (Figure 3). The median annual natural recharge of the CPA is estimated to be $230 \mathrm{MCM}$ while the return flow from irrigation is estimated to be $30 \mathrm{MCM}$. Approximately $37 \mathrm{MCM} / \mathrm{Y}$ infiltrates from the east, while about $135 \mathrm{MCM} / \mathrm{Y}$ is recharged artificially. The artificial recharge is derived from: $\sim 120 \mathrm{MCM}$ treated wastewater from the Shafdan plant in Tel-Aviv, and 15 MCM of flood water from the Shiqma project in the southern coastal plain $(\sim 5 \mathrm{MCM} / \mathrm{Y})$ and the Menashe project in the northern coastal plain $(\sim 10 \mathrm{MCM} / \mathrm{Y})$. Currently overall, approximately $430 \mathrm{MCM}$ are recharged while $420 \mathrm{MCM}$ are pumped out, and $20 \mathrm{MCM}$ flow to the sea. Historically, the most intensive pumping from the aquifer occurred during the 50's and 60's. In the period 1934-1963 the water storage of the aquifer decreased by $2200 \mathrm{MCM}$. The lowest water levels were observed in the mid-80's (water storage in 1986 was by 2800 MCM 


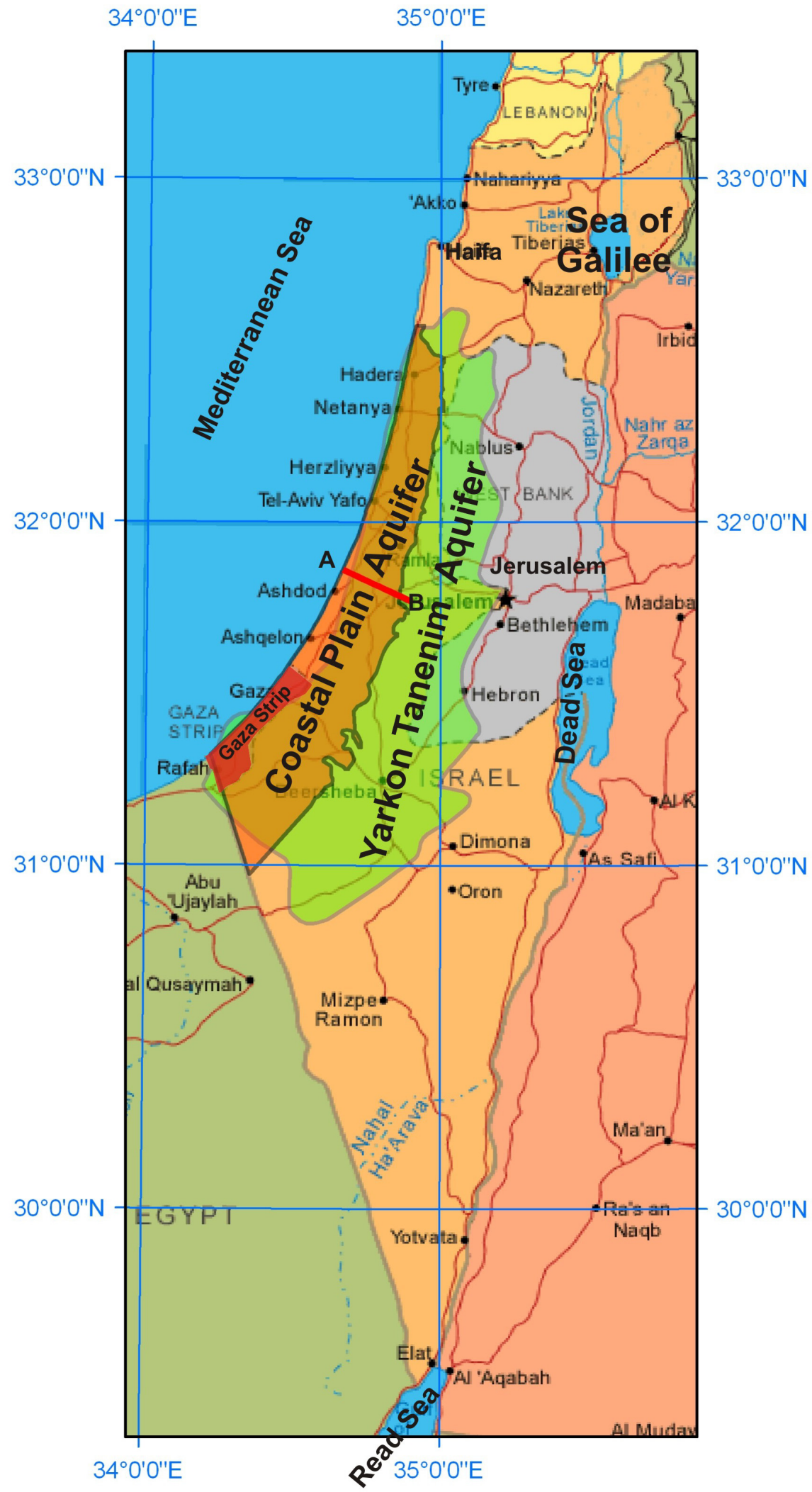

Figure 1. Location map. 


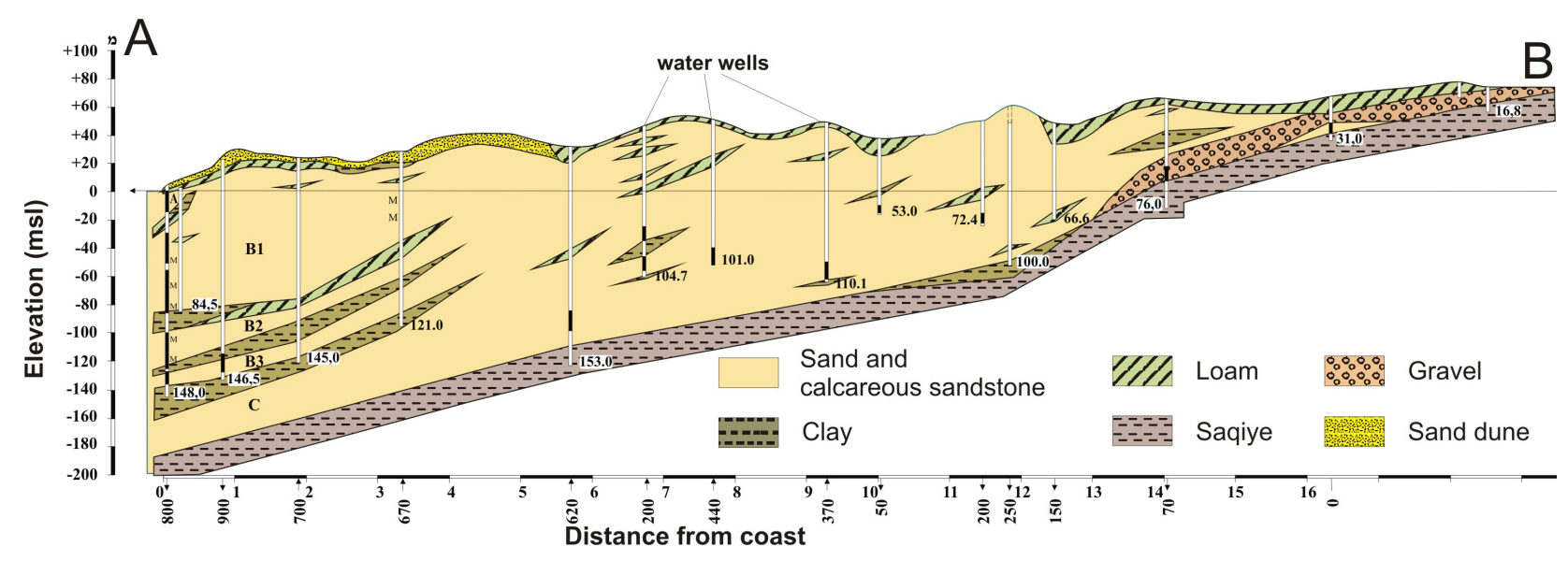

Figure 2. Typical hydrogrological cross-section, modified after Tolmach, 1978 [10].
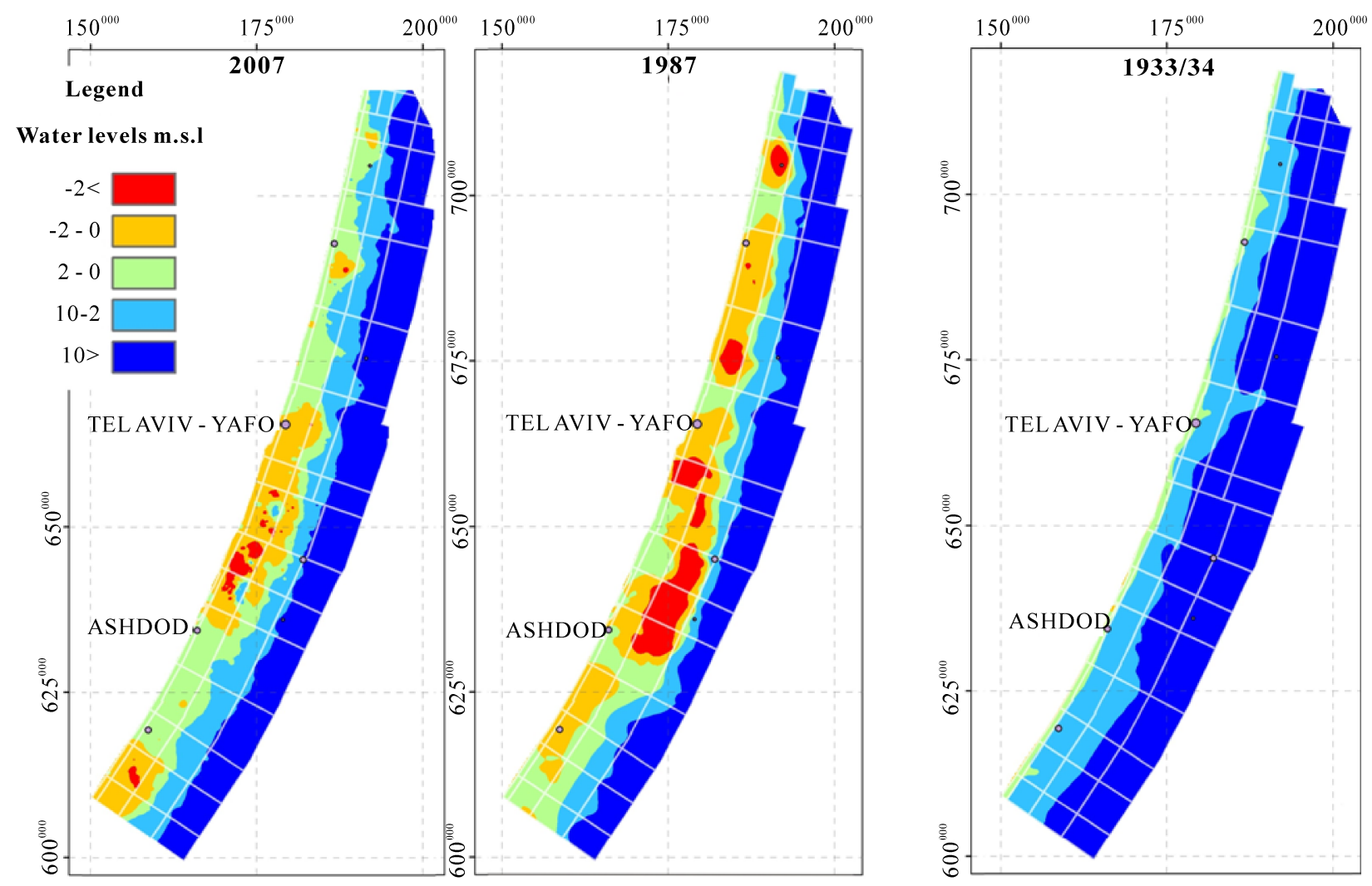

Figure 3. Water levels in coastal aquifer (m.s.l) in 1934, 1987 and 2007.

lower than in 1934). In 2007 the water storage in the aquifer was $2100 \mathrm{MCM}$ lower than in 1934 [8].

The natural salinity (1934) of the water in the CPA was relatively low, less than $250 \mathrm{mg} / \mathrm{L}$ chloride in most parts of the aquifer (Figure 4). As can be seen from Figure 4, aquifer water salinity has increased sharply since 1934, and in the year 2007 ground water salinity in most parts was significantly higher then $250 \mathrm{mg} / \mathrm{L}$ of chloride. Since 1934 the total mass of chloride in the groundwater has doubled from approximately 3.5 million tons to approximately 7 tons. This estimation of Livshitz and Zentner [8] didn't include the salt addition due to sea water intrusion in the western part of the aquifer.

As mentioned, the deterioration of the groundwater quality in the western part of the CPA is due to pumping which exceeded the inflow and thus caused the penetration of the seawater from the west. Water in some of the southeastern parts of the CPA has become brackish (600 

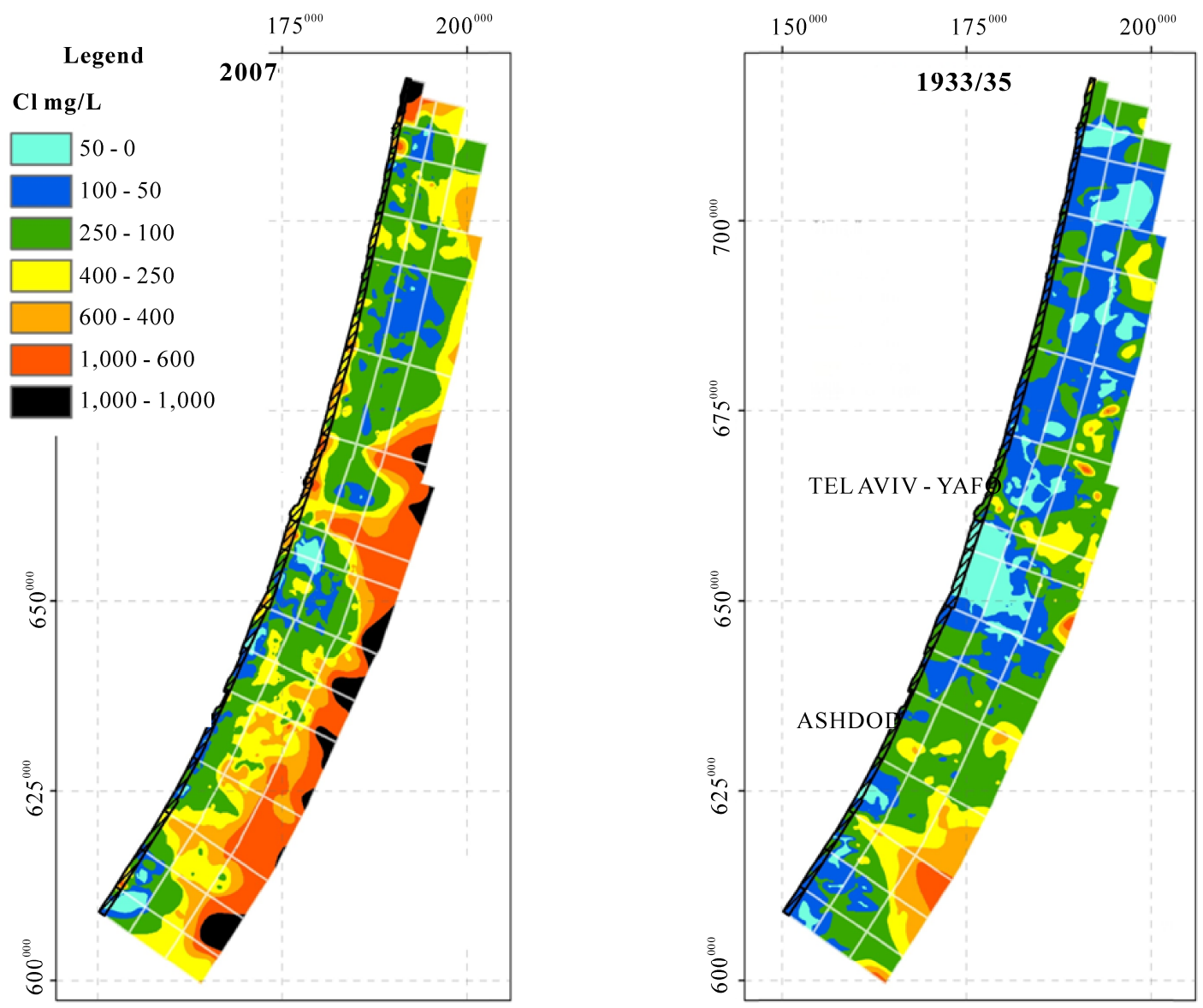

Figure 4. Water salinity in the coastal plain aquifer (mg/L of chloride) in 1934 and 2007.

to $1500 \mathrm{mg} / \mathrm{L} \mathrm{Cl}$ ). This is due to seepage from semipermeable chalks of Eocene age which border the CPA on the east [9]. Another factor leading to the deterioration of the groundwater quality is the reduction of recharge due to the fact that this region is densely populated and the outcrops were covered by buildings and pavements. Infiltration of water from irrigation, part of which is reclaimed sewage (mostly between 250 and $400 \mathrm{mg} / \mathrm{L}$ chloride), and artificial recharge by water brought by the National Carrier from the Sea of Galilee (average salinity $240 \mathrm{mg} / \mathrm{L}$ ), as well as contamination by industrial wastes, lowered further the quality of the groundwater.

The Hydrological Service of Israel estimates that in 2008 the salt addition from natural recharge is about 16,000 tons of chloride, while irrigation and brackish water from the west adds about 50,000 and 30,000 tons, respectively. An additional 40,000 tons of chloride are recharged into the CPA by the Shafdan project, which is the sewage reclamation project of Tel-Aviv and its surrounding the urban centers. The outflow of chloride by pumping is estimated to be 85,000 tons which is significantly lower (about 50,000 tons) than the chloride inputs.
This estimation doesn't include addition of salts due to sea water intrusion in the western part of the aquifer.

Irrigation on the coastal plain contributes to the underlying groundwater quality not only in terms of chloride, but also provides high quantities of nitrates and pesticides. In some CPA wells, nitrate concentrations are as high as $100 \mathrm{mg} / \mathrm{L}$. This problem is especially pronounced in the northern part of the aquifer where whole areas cannot be used for potable water supply because of high nitrate concentration.

As mentioned above, Issar and Zohar [1] claimed that global warming was the cause for the decrease in the annual average precipitation, which will cause the diminution of the natural recharge and will thus cause additional degradation of the quality of the groundwater in the CPA.

The official policy with regard to the water quality of the CPA is to invest resources in order to remediate the groundwater quality and bring it to drinking water standards. This policy is in accordance with the policy of "Sustainable Development", which rejects any development, which will comprise "the ability of future generations to meet their own needs". The question is whether 
the remediation measures are feasible in view of the prediction of a warmer climate and thus reduction of precipitation and a simultaneous increase of population. The decreasing supply and increasing demand will most probably result in the deterioration of the quality of water rather than remediation. Thus a realistic rather than an impractical approach would be the development of the CPA by steps preventing uncontrolled processes which would cause the collapse of the hydro-chemical regime. For this purpose the policy of "Sustainable Development" has to be replaced by that of Progressive Development. This policy takes into consideration the need of taking daring steps which although they may "compromise the ability of future generation etc." will allow the chance of ensuring future supply by creating a new hydrological and hydro-chemical balance.

\section{Progressive Development of a New Hydro-Chemical Balance}

The present study concentrates on the scientific and technical issues of the development of the water resources in the central and humid part of Israel. Depending on the way the political issues of the region will be solved, future development of water resources may have to consider supply to other populations in the region besides Israeli, Palestinian or Jordanian, yet the issue of future plans depends very much on the way the political issues will be solved.

Currently the Israel Water Authority is developing several projects that should prevent the future decline in water quality of the CPA. These projects include: improving effluent quality (upgrading existing treatment plants and decreasing the salinity of supplied water), pumping and treatment of contaminated water (mainly nitrate contamination), water-sensitive urban planning and providing subsurface capacities for recharged desalinized water. An important new project, Rehabilitation of the Coastal Plain Aquifer, includes drilling a line of pumping wells in the eastern part of the coastal plain. These wells will provide drainage that will prevent the percolation of brackish water from the adjacent Eocene chalk aquifer. Desalination plants for brackish water will be integrated into the local water supply system to provide farmers with irrigation water (mainly effluents) of low salinity (less then $150 \mathrm{mg} / \mathrm{L}$ of chloride). In this area, pumping will be decreased to $3 / 4$ of the natural recharge in order to increase overall water storage availability for dry years.

Thus although the official reference to these steps is that they are taken in the framework of Sustainable Development, it is claimed here that they are actually in accord with Progressive Development. This claim is based on the fact that this plan takes into consideration certain deterioration in the quality of the groundwater in specific areas in order to be able to provide sufficient water storage during periods of drought. It is important to point out that the amount of sea water desalinization suggested by the Water Authority and accepted by the State of Israel takes into account a $10 \%$ decrease in natural recharge as a result of global warming. However, the green lines suggested as optimal levels for water resources operation do not take into consideration the need for long tem water storage.

As was shown in the previous section, the current water storage in the CPA is about 2000 MCM less than in the mid-30's. It is important to point out that the mid-30's experienced one of the hardest droughts in the last 150 years and that the water levels were particularly low.

The problem with re-injecting water into the CPA at high levels is the increased gradient seaward (westward), i.e. loss, of fresh groundwater. In the mid-30's about $120 \mathrm{MCM} / \mathrm{Y}$ were discharged into the sea. Currently this discharge is estimated as $20 \mathrm{MCM} / \mathrm{Y}$. We suggest that this problem can be solved by the artificial management of the sea water intrusion area. This management will include two sets of pumping wells. The pumping wells in the fresh water body will preserve groundwater heads while the pumping wells in the saline water body will decrease the heads. The pumped fresh water will be integrated into the water supply system and the saline water, having salinity close to Mediterranean Sea water, will be desalinated or supplied for other needs (swimming pools, air-conditioners etc.) instead of fresh water. Desalinization of seawater pumped from the interface is significantly cheaper than that from the sea (there is no need for pre-treatment).

In the eastern part of the aquifer the effort should be invested to stabilize the quality of the groundwater as second grade water, namely adequate for all general household uses except drinking. Measures to guarantee this will include the recharge of rainwater and surface flow, which currently flow to the sea, and the prevention of recharge by saline and toxic wastewater. This part of the aquifer can be used for the storage of treated effluents in the winter time and reuse during wet years. In the long term, the recharge of low salinity water into the eastern part of the aquifer (salinity of effluents expected to be around $200 \mathrm{mg} / \mathrm{L}$ of chloride) will decrease groundwater salinity. However, this will be offset by the higher water levels which will prevent the percolation of brackish water from the adjacent Eocene aquifer. This policy will ensure that the CPA serves as a long term water storage reserve of about $2000 \mathrm{MCM}$ with the western part of the aquifer used for storage of potable water, and the eastern part for storage of second grade water, and will prevent the sea water intrusion due to rising sea level resulting from global worming.

Albeit in the future the bulk of the fresh water supply for the entire region will come primarily from seawater 
desalination plants, and secondarily from desalinated brackish water, once a series of dry years occurs (as is the case of the last 5 years which may continue), the groundwater storage can be utilized.

Due to paleo-environmental conditions, which existed during the Quaternary period, all the riverbeds, which cross the Coastal Plain, are underlain by thick layers of clay. Moreover, adequate natural sites for storage dams are very rare in the central and western parts of the Coastal Plain. These conditions dictate that the best places for storage and later gradual recharge of the floods are in the eastern parts of this region, close to the foothills.

As part of the new cooperative planning with the Palestinians, following the model of Progressive Development, remediation in the part of the Coastal Plain underlying the Gaza Strip should follow a similar policy, namely the reclamation of the water table, but not of the water quality, in order to prevent further invasion of sea interface. This will enable the recovery of the overpumped aquifer below the Gaza Strip. This can only be done once the gap between supply and demand in this region will be supplied from desalinization projects and waste water reuse.

\section{References}

[1] A. S. Issar and M. Zohar, "Climate Change: Environment and History of the Near East," Springer-Berlin, Heidelberg, New York, 2007.
[2] P. Alpert, S. O. Krichak, H. Shafir, D. Haim and I. Osetinsky, "Climatic Trends to Extremes Employing Regional Modeling and Statistical Interpretation over the E. Mediterranean," Global and Planetary Change, Vol. 63, No. 2-3, September 2008, pp. 163-170.

[3] A. S. Issar, "Progressive Development in Arid Environments: Adapting the Concept of Sustainable Development to a Changing World," Hydrogeology Journal, Vol. 16, No. 6, September 2008, pp. 1229-1231.

[4] A. S. Issar, "Progressive Development to Sustain Food Supply in the Arid and Semi-Arid Regions (ASAR)," Journal of Arid Environments, Vol. 73, No. 3, March 2009, pp. 396-397.

[5] "Hydrological Service of Israel," Status Report, in Hebrew, 2007.

[6] "Hydrological Service of Israel," Status Report, in Hebrew, 2008.

[7] A. Issar, "Geology of the Central Coastal Plain of Israel," Israel Journal of Earth-Science, Vol. 17, 1968, pp. 16-29.

[8] Y. Livshitz and Zentner, "Changes in the Water and the Salt Storage of Israeli Coastal Plain Aquifer since 30's," Israeli Hydrological Service Report, in Hebrew, in Press, 2010.

[9] Y. Livshitz, "The Influence of Natural and Artificial Factors on the Chemical Composition of the Groundwater in the Northwestern Negev and the Southern Portion of the Shfela," Ph.D. Dissertation, in Hebrew, Ben-Gurion University, Negev, 1999.

[10] Y. Tolmach, "Hydrogeological Atlas of Israel, Coastal aquifer, Ashdod Area," Israeli Hydrological Service Report, in Hebrew, 1978. 